\title{
A survey of the availability in Canadian pharmacy chains of over-the-counter natural health products for menopause symptoms
}

\author{
Jennifer Croden', Sue Ross ${ }^{1}$, Nese Yuksel ${ }^{2}$ and Beate C Sydora ${ }^{1 *}$
}

\begin{abstract}
Background: Menopause is a natural phase in a woman's aging process, characterized by the cessation of menstruation. Women who are going through the menopause transition can experience physiological symptoms that significantly impact their quality of life. Concern about adverse effects of traditional hormone therapy often leads women to purchase over-the-counter (OTC) natural health products (NHPs). The goal of this study was to investigate the range of OTC NHPs for menopause available to Canadian women, and the packaging information they can access to make self-management decisions.
\end{abstract}

Methods: Edmonton stores belonging to each of nine Canadian pharmacy chains were visited to identify NHPs marketed for the relief of menopausal symptoms. Details were extracted from the packaging: a) product name and manufacturer, b) Health Canada license number, c) medically active ingredients, d) claims of efficacy, e) contra-indications and warnings, and f) daily cost. Data were entered and analyzed using Microsoft Excel.

Results: We identified 20 OTC NHP menopausal products, 19 of which had Health Canada license numbers. Twentyeight medically active ingredients were identified, with the most common being black cohosh (in 14 products) and soy isoflavones $(n=7)$, chaste tree $(n=5)$, and dong quai $(n=3)$. Most products claimed they would relieve vasomotor symptoms, including hot flashes $(n=14)$ and night sweats $(n=10)$. Each product had a labeled contraindication for at least one specific condition. Costs per recommended daily dose ranged from $\$ 0.07$ to a maximum of $\$ 2.50$ (CAD\$).

Conclusion: Natural health products for menopausal symptoms are easily available to Canadian women. The lack of clear evidence of product efficacy makes the need for easily accessible, balanced information on this topic important for women to make well informed choices.

Keywords: Over-the counter products, Natural health products, Menopause, Menopause symptoms, Women's choice

\section{Background}

Menopause is a natural phase in a woman's aging process characterized by the cessation of menstruation. The majority of women experience physiological symptoms that significantly impact their quality of life. The most common symptoms reported are hot flashes and night sweats, with $50-85 \%$ of perimenopausal women experiencing vasomotor instability [1]. Depressed mood, urogenital changes, and sleep disturbances are other symptoms

\footnotetext{
* Correspondence: bsydora@ualberta.ca

'Department of Obstetrics and Gynecology, Faculty of Medicine and

Dentistry, University of Alberta, 5S131 Lois Hole Hospital for Women, Robbins Pavilion, Royal Alexandra Hospital, 10240 Kingsway Avenue NW, Edmonton, AB T5H 3 V9, Canada

Full list of author information is available at the end of the article
}

commonly experienced by women during menopause [2]. While traditional hormone therapy has been found to be approximately $90 \%$ effective in reducing vasomotor symptoms [3], results of clinical trials implicating the therapy in the increased risk of cardiac events, strokes, and breast cancer [4-6] have caused women to seek alternative remedies for menopausal symptoms. Women wish to be actively involved in their choice of alternative treatments [7]. Canadian surveys suggest that as many as 60 to $90 \%$ of women may consider taking complementary and/or alternative medicine for menopause symptoms $[8,9]$, but are concerned about obtaining credible advice and the cost of alternative treatments [7]. 
Natural health products (NHPs) licensed by Health Canada for sale over-the-counter (OTC) without a prescription include vitamins, minerals, herbal remedies, and homeopathic medicines. All NHPs sold in Canada are required to have a Health Canada product license (designated by an eight-digit Natural Product Number $(\mathrm{NPN})$ ), which indicates that safety, quality, and efficacy evidence has been assessed [10,11]. For Health Canada licensing of NHPs, efficacy evidence is required in proportional to the risk inherent in the treated condition; for example, a NHP for treating a high risk condition (one that is life-threatening without effective treatment) requires strong, corroborated evidence of efficacy, while a NHP for a low risk condition (a minor condition that may resolve itself over time) requires less efficacy evidence [10,11]. Health Canada currently approves 448 products for menopause sale consisting of single and multiple active ingredients. While there have been studies into the effectiveness of different NHPs for treating menopausal symptoms, opinions over the efficacy of these products remains mixed [12-17].

Natural health products are widely available for purchase in pharmacies across Canada, and pharmacies are considered by women as a significant resource to support decision-making [7]. Our research, a survey of NHPs sold in Canadian pharmacies, set out to identify both the range of OTC products that are available for women who are seeking non-hormonal alternatives for relief of their menopause symptoms, and the information available on product packaging to help them make their self-management decisions.

\section{Methods}

Our descriptive study was a survey of OTC NHPs that are available to woman seeking OTC relief for menopausal symptoms in Canada-wide pharmacies in a single city, Edmonton.

\section{Pharmacy selection}

We included nine pharmacy chains with retail stores in Edmonton, Alberta, selected to include a range of retail types (specialized pharmacy chain, grocery or department stores with in-house pharmacies). Only chains with retail stores in four or more Canadian provinces or territories were included in our study. In June 2014, one location for each of the nine pharmacy chains was visited in order to provide a snapshot of the available NHPs for menopause. The identity and availability of relevant products was initially documented in-store in June 2014.

\section{Product selection}

Natural health products and OTC remedies were included if the product information found on the packaging stated that its recommended use was for menopause symptoms (solely or among others). Products that claimed relief for other symptoms that may be seen in menopause (i.e. sleep, anxiety) but did not specifically mention "menopause" were excluded. The name, manufacturer and NPN for each product were noted. One container of each product identified was purchased.

\section{Data extraction}

The following data items that women might consider when selecting a NHP were collected from the packaging for each individual product:

- Name and quantity of each active ingredient in the product

- Recommended indications of the product

- Contraindications and warnings of the product

- Recommended daily dose for each product

- Cost per package (CAD\$)

\section{Data analysis}

All data were entered into a Microsoft Excel spreadsheet to categorize product and ingredient data.

Cost per recommended daily dose was calculated for each product for each store where it was identified by dividing the retail price by the number of tablets or capsules sold and multiplying by the average recommended daily dose as stated on the product's package. The range of costs per daily dose is presented for products sold in more than one store at different retail prices.

Excel's statistical analysis tools were used to calculate the range, mean, and standard deviation of numerical data as necessary.

\section{Results}

\section{Natural health products}

In the nine selected Canadian pharmacy chains we identified and purchased a total of 20 OTC NHPs available for relief of menopausal symptoms between 13 October and 18 November 2014. The median number of products available per pharmacy was eight, with a range of two to 12 products. Details of the individual products are described in Tables 1 and 2.

\section{Regulatory approval}

Nineteen of the products were labeled with an NPN (Table 1). One product had no available information regarding its regulatory approval. Three of the black cohosh products had the same NPN, indicating that each of these store "own brand" products were made under license by the same manufacturer, in this case WN Pharmaceuticals.

\section{Ingredients}

A total of 28 different active ingredients were identified. The number of active ingredients per product varied 
Table 1 Details of the product, active ingredients, daily dose and cost per dose

a. Products with multiple active ingredients

\begin{tabular}{ll}
\hline Product name/Manufacturer & Health \\
& Canada \\
& Licence \\
& Number
\end{tabular}

Ingredients active for menopause symptoms,
amount per tablet 5 most common active
amount per tablet 5 most common active ingredients in bold

Swiss Natural HRT ${ }^{\oplus}$ Regular/

Valeant Canada LP/S.E.C.

Swiss Natural HRT ${ }^{\oplus}$ Extra

Strength/Valeant Canada LP/S.E.C.

Swiss Natural HRT ${ }^{\oplus}$ Nightime/ Valeant Canada LP/S.E.C.

Estroven $/$ i-Health, Inc.

Estroven ${ }^{\oplus}$ Maximum Strength/i-Health, Inc.

Life Brand ${ }^{\mathrm{TM}}$ Menopause Relief/GFR Pharma Ltd.

femMED ${ }^{\circledR}$ Menopause Relief/ femMED Formulas Inc.

webber naturals ${ }^{\oplus}$

FemmeCalm Menopause

Formula/WN

Pharmaceuticals Ltd.

MENOsmart ${ }^{\text {TM }}$ Plus/Lorna

Vanderhaeghe Health

Solutions, Inc.

80038543

80038543

80019270 Black cohosh (100 mg), chaste tree (200 mg),

Black cohosh (30 mg), chaste tree (100 mg),

soy isoflavones $(70 \mathrm{mg})$, wild yam $(50 \mathrm{mg})$,

burdock (50 mg) soy isoflavones $(100 \mathrm{mg})$, wild yam $(50 \mathrm{mg})$, burdock (100 mg)

80002152 Black cohosh (100 mg), lemon balm (300 mg), passion flower (150 mg)

80024706 Black cohosh (40 mg), soy isoflavones (37.5 mg), calcium (150 mg), folic acid (400 $\mu \mathrm{g})$, kudzu (100 mg), magnolia (15 mg), vitamin E (30 IU), thiamin (2 mg), riboflavin $(2 \mathrm{mg})$, niacinamide $(20 \mathrm{mg})$, vitamin B6 $(10 \mathrm{mg})$, vitamin B12 $(6 \mu \mathrm{g})$, selenium $(70 \mu \mathrm{g})$, boron glycinate $(1.5 \mathrm{mg})$, Chinese-date seed $(120 \mathrm{mg})$

80032569 Black cohosh (80 mg), calcium (138 mg), chaste tree 1, daily

$\$ 1.00-\$ 1.17$ (75 mg), folic acid (400 $\mu \mathrm{g})$, green tea $(60 \mathrm{mg})$, soy isoflavones $(102.5 \mathrm{mg})$, vitamin D3 $(25 \mu \mathrm{g})$, vitamin $\mathrm{E}$ (30 IU), thiamin (5 mg), riboflavin (5 $\mathrm{mg})$, niacinamide (20 mg), vitamin B6 (20 mg), vitamin B12 (25 $\mu$ g), selenium $(70 \mu \mathrm{g})$, boron glycinate $(1.5 \mathrm{mg})$, chromium $(120 \mu \mathrm{g})$, L-theanine $(50 \mathrm{mg})$, caffeine $(49 \mathrm{mg})$, cranberry $(25 \mathrm{mg})$

Not available

Black cohosh (20 mg), red clover isoflavones

(42 mg), soy isoflavones (425 mg)

80025767 Black cohosh (40 mg), dong quai (125 mg), pomegranate $(75 \mathrm{mg})$, damiana $(75 \mathrm{mg})$, partridge berry $(75 \mathrm{mg})$, motherwort $(50 \mathrm{mg})$, schizandra (50 mg)

80046012 Black cohosh $(80 \mathrm{mg})$, chaste tree $(80 \mathrm{mg})$, dong quai $(100 \mathrm{mg})$, gamma-oryzanol $(75 \mathrm{mg})$, hesperidin (30 mg)

80025898 Black cohosh (80 mg), chaste tree $(80 \mathrm{mg})$, dong quai $(100 \mathrm{mg})$, gamma-oryzanol $(75 \mathrm{mg})$, hesperidin (75 mg), sage (75 mg)
Recommended Range of cost of daily dose (\# of average daily tablets, frequency) recommended $\operatorname{dose}^{\mathrm{a}}$ (CAD\$)

1, twice daily \$0.36-\$0.93

1, daily

$\$ 0.18-\$ 0.47$

1, at night

$\$ 0.36-\$ 0.47$

1, daily

$\$ 0.61-\$ 0.86$

\begin{tabular}{|c|c|c|c|c|}
\hline Product name/Manufacturer & $\begin{array}{l}\text { Health } \\
\text { Canada } \\
\text { Licence } \\
\text { Number }\end{array}$ & $\begin{array}{l}\text { Ingredients active for menopause } \\
\text { symptoms, amount per tablet }\end{array}$ & $\begin{array}{l}\text { Recommended } \\
\text { daily dose (\# of } \\
\text { tablets, frequency) }\end{array}$ & $\begin{array}{l}\text { Range of cost } \\
\text { of average daily } \\
\text { recommended } \\
\text { dose }^{\mathrm{a}} \text { (CAD\$) }\end{array}$ \\
\hline $\begin{array}{l}\text { up\&up }{ }^{\text {TM }} \text { Black Cohosh/WN } \\
\text { Pharmaceuticals Ltd. }\end{array}$ & $80007421^{b}$ & Black cohosh (40 mg) & 1-2, daily & $\$ 0.24$ \\
\hline $\begin{array}{l}\text { London Naturals } \text { Black Cohosh/ } \text { WN Pharmaceuticals Ltd. }\end{array}$ & $80007421^{b}$ & Black cohosh (40 mg) & 1-2, daily & $\$ 0.27$ \\
\hline $\begin{array}{l}\text { equate }{ }^{\oplus} \text { Black Cohosh/Nita } \\
\text { Health Products Inc. }\end{array}$ & 02238871 & Black cohosh (40 mg) & 1, daily & $\$ 0.12$ \\
\hline $\begin{array}{l}\text { Holista }{ }^{\oplus} \text { Black Cohosh/ } \\
\text { Holista Health (Canada) Inc. }\end{array}$ & 80010287 & Black cohosh (40 mg) & 1-2, daily & $\$ 0.07-\$ 0.09$ \\
\hline $\begin{array}{l}\text { Be.better } r^{\mathrm{TM}} \text { Black Cohosh/WN } \\
\text { Pharmaceuticals Ltd. }\end{array}$ & $80007421^{b}$ & Black cohosh (40 mg) & 1-2, daily & $\$ 0.29$ \\
\hline $\begin{array}{l}\text { Promensi }{ }^{\oplus} \text { Regular Strength/ } \\
\text { PharmaCare Laboratories }\end{array}$ & 80015467 & Red clover isoflavones (40 mg) & 1, daily & $\$ 0.67-\$ 1.10$ \\
\hline $\begin{array}{l}\text { Promensil }{ }^{\oplus} \text { Double Strength/ } \\
\text { PharmaCare Laboratories }\end{array}$ & 80016071 & Red clover isoflavones (80 mg) & 1, daily & $\$ 1.23-\$ 1.33$ \\
\hline
\end{tabular}


Table 1 Details of the product, active ingredients, daily dose and cost per dose (Continued)

\begin{tabular}{|c|c|c|c|c|}
\hline $\begin{array}{l}\text { webber naturals }{ }^{\otimes} \text { Soy Isoflavone } \\
\text { Complex/WN Pharmaceuticals Ltd. }\end{array}$ & 80015647 & Soy isoflavones (50 mg) & 7, daily & $\$ 0.77$ \\
\hline $\begin{array}{l}\text { Menoconfort Forté } \mathrm{C} / \mathrm{IRB} \text { Yves } \\
\text { Ponroy Canada Inc. }\end{array}$ & 80021605 & Soy isoflavones $(300 \mathrm{mg})^{c}$ & 1, at night & $\$ 0.55$ \\
\hline i-Coolø/i-Health, Inc. & 80033608 & Synthetic soy isoflavones, genistein (30 mg) & 1, daily & $\$ 0.83-\$ 0.87$ \\
\hline $\begin{array}{l}\text { A. Vogel }{ }^{\mathrm{TM}} \text { Menopause/Bioforce } \\
\text { Canada Inc. }\end{array}$ & 80034857 & Sage (3400 mg) & 1,1 to 5 times daily & $\$ 2.33-\$ 2.50$ \\
\hline
\end{tabular}

Notes: ${ }^{\text {a }}$ products without a range of daily cost were either only found in a single pharmacy or found in several pharmacies at a single price.

${ }^{b}$ products share the same licence number.

"Menoconfort Forté packages include a daytime NHP for "radiant skin".

from one to 19. Nine products contained multiple active ingredients, while eleven products contained a single active ingredient. The most common active ingredients were black cohosh (14 products), soy isoflavones $(n=7)$, chaste tree $(n=5)$, dong quai $(n=3)$ and red clover isoflavones $(n=3)$.

\section{Claims of efficacy and safety}

In accordance with our product selection criteria every OTC product made a menopause symptom health claim. Fifteen of the 20 products asserted they were effective in alleviating "general menopausal symptoms" with or without specific symptom benefits. Fourteen of the 20 products claimed relief from vasomotor symptoms (Table 2), specifically hot flashes $(n=14)$ and night sweats $(n=10)$. One product claimed relief from urogenital symptoms, including vaginal dryness and low libido (Table 2). Four products claimed they would contribute to reduced bone loss if taken with sufficient Vitamin D and calcium (Table 2).

Each product had labeled contraindications for at least one specific condition. There was considerable overlap between contraindications reported, even though the active ingredients were different (Table 2). Eighteen of the NHPs warned against the use of the product with liver dysfunction and 17 warned against their use while pregnant or breastfeeding. Many of the products had a labeled contraindication involving the use of the product with blood thinning medications ( $\mathrm{n}$ =9) or hormone replacement therapy $(n=10)$. Other frequent contraindications included the use of the product with hormone-associated gynecological disorders such as endometriosis or cancers $(n=10)$ or history of or current breast cancer $(n=10)$. Warnings were usually about stopping taking the product in the event of new-onset liver symptoms or breast pain, or development of an allergy to any of the ingredients.

\section{Cost}

The cost of the average recommended daily dose (CAD\$) for each product varied widely, from a minimum of $\$ 0.07$ to a maximum of $\$ 2.50$ (Table 1). The cost of the recommended daily dose of single ingredient products on average (mean (SD) $\$ 0.71( \pm \$ 0.53)$ ) was found to be identical to, but vary more than, the average daily cost of combination products $(\$ 0.71(+\$ 0.30))$. Sale prices were responsible for some products being sold at bargain prices.

\section{Discussion}

Our investigation revealed that Canadian pharmacy chains sold a variety of NHPs that claim they can provide relief from menopausal symptoms. Our study aimed to be as relevant as possible to the experience of women throughout Canada seeking over-the-counter assistance through the menopause transition. We explored the packaging information easily available to women making decisions in pharmacies about which menopause-related NHP to use. The descriptions of indications for use and contraindications are remarkably similar between the menopause treatments and therefore the cost of treatment becomes an important factor. According to our findings, the annual cost of purchasing OTC NHPs for menopausal symptoms can range from $\$ 29.20$ to $\$ 872.35$ (CAD\$) for the average Canadian woman.

Natural health products available OTC for menopausal symptoms are assessed and licensed on the basis of safety and efficacy as per Health Canada's regulation standards. However, while Health Canada requires evidence of the association of active ingredients with the health claim made by the product, the type and amount of evidence required depends directly on the health impact on consumers if the product does not work as expected. Menopause is considered a low-risk condition by Health Canada, in that symptoms are not life threatening and have the potential to resolve themselves over time [10], and Health Canada requires minimal efficacy evidence for natural health products in the low-risk category [11]. The Health Canada regulations stipulate that the details provided on the labels of licensed NHPs must include information on risks and possible interactions with conventional treatments. Furthermore, Health Canada requires that all NHP manufacturers have a site license, signifying that the site is able to maintain proper 
Table 2 Indications and contraindications/warnings for each product

Product

\section{Indications}

Contraindications/warnings

Menopause Vasomotor Sleep Mood Other Pregnancy/ Hormonal

Pregnancy/ Hormonal
breastfeeding

Breast Liver Allergy to Blood disorders, cancer

HRT/thyroid Other medication

Products with multiple active ingredients

Swiss Natural HRT

Regular

Swiss Natural HRT ${ }^{\circledR}$

Extra Strength

Swiss Natural HRT

Nightime

Estroven ${ }^{\oplus}$

Estroven ${ }^{\circledast}$ Maximum

Strength

Life Brand ${ }^{\mathrm{TM}}$

Menopause Relief

femMED ${ }^{\circledR}$

Menopause Relief

FemmeCalm Menopause

Formula

MENOsmart ${ }^{\text {TM }}$

Products with single active ingredient

\begin{tabular}{|c|c|c|c|c|c|c|c|c|c|c|c|c|c|}
\hline up\&up ${ }^{\text {TM }}$ Black Cohosh & + & - & - & - & & + & - & - & + & - & - & - & ' \\
\hline $\begin{array}{l}\text { London Naturals } \\
\text { Black Cohosh }\end{array}$ & + & - & - & - & & + & - & - & + & - & - & - & \\
\hline equate ${ }^{\circledast}$ Black Cohosh & + & - & - & - & & + & - & - & + & + & - & - & $\begin{array}{l}\text { May cause } \\
\text { drowsiness }\end{array}$ \\
\hline Holista ${ }^{\circledast}$ Black Cohosh & + & - & - & - & & + & - & - & + & - & - & - & \\
\hline Be.better ${ }^{\text {TM }}$ Black Cohosh & + & - & - & - & & + & - & - & + & - & - & - & \\
\hline $\begin{array}{l}\text { Promensil }{ }^{\oplus} \text { Regular } \\
\text { Strength }\end{array}$ & + & + & - & - & $\begin{array}{l}\text { Bone \& heart } \\
\text { health }\end{array}$ & + & + & + & + & + & + & + & \\
\hline $\begin{array}{l}\text { Promensil }{ }^{\circledR} \text { Double } \\
\text { Strength }\end{array}$ & + & + & + & + & $\begin{array}{l}\text { Bone \& heart } \\
\text { health, vaginal } \\
\text { dryness }\end{array}$ & + & + & + & + & + & + & + & \\
\hline Soy Isoflavone Complex & + & + & - & - & Bone health & - & + & + & + & - & + & + & \\
\hline Menoconfort Forté & + & + & - & - & & - & + & + & + & - & + & + & \\
\hline $\mathrm{xi}^{-\mathrm{CoO}}{ }^{\oplus}$ & + & + & - & - & & - & + & + & + & - & + & - & \\
\hline A. Voge ${ }^{\mathrm{TM} M}$ Menopause & + & + & - & - & & + & - & - & - & + & - & - & Epilepsy \\
\hline
\end{tabular}

$\mathrm{el}^{\mathrm{TM}}$ Menopause 
production, labeling, handling, and distribution of the products made there [18]. Health Canada rules on compliance with labeling [19] ensure that the proper protocol for labeling is being followed and the necessary information is being provided to consumers. However, the volume of mandatory information means that the labels use very small font sizes in order to provide the details in two languages, making the warnings inaccessible to anyone with poor eyesight or lack of understanding of the terms used. Potential purchasers might find information about warnings of possible risks unsettling [20] and seek additional information from pharmacists who must be prepared to answer detailed questions about the NHPs [21].

There have been many studies assessing NHP supplementation for relief of menopausal symptoms [for example 12-17]. However, the findings have been inconsistent, and the quality and heterogeneity of studies has reduced the number of trials that can be combined in systematic reviews or meta-analyses. An Australian systematic review carried out on OTC products for relief of hot flashes in menopausal women found contradictory research evidence of NHP supplementation's effectiveness, concluding that the inconsistent data did not support the use of OTC products for menopausal symptoms [12].

Black cohosh has generated the most research interest as a treatment for menopause symptoms, of relevance to the results of our study which found that black cohosh was the most commonly available active ingredient, present in 70\% of the products we identified. A 2012 Cochrane review of randomized controlled trials assessing black cohosh versus placebo or other treatments found that black cohosh did not significantly reduce hot flashes or menopausal symptom scores, whereas hormone treatment (compared to black cohosh) reduced symptom scores significantly [13]. A 2015 extensive review of effects of herbal preparations on symptom clusters in menopause suggested that black cohosh had a significant effect on hot flashes [22], but this observation was based on qualitative review of the research, rather than the more rigorous quantitative methods used in the Cochrane review of randomized trials [13].

Black cohosh has been suspected of being linked to liver disorders, although cases are rare and can seldom be attributed directly to black cohosh [14]. Evidence on safety of black cohosh from the Cochrane review was inconclusive because of inadequate reporting [13], and the more recent review suggested that the incidence of adverse effects associated with black cohosh did not differ from those associated with placebo [22].

A Cochrane review of the evidence supporting phytoestrogens (including soy and red clover isoflavones) for menopausal vasomotor symptoms produced no conclusive evidence that phytoestrogen supplementation effectively reduced the frequency or severity of hot flashes and night sweats [15]. A sub-group of trials comparing Promensil (red clover isoflavones) to placebo did not find a significant reduction in hot flashes [15]. A recent meta-analysis of the efficacy of phytoestrogens versus placebo indicated that hot flash frequency was reduced compared to placebo, but there was not a significant treatment effect of phytoestrogens on menopause symptoms more generally [16]. In the few studies that reported side effects, there was no significant difference between phytoestrogen and placebo [16]. A systematic review including chaste tree and black cohosh did not find either was more effective than the placebo in treating climacteric complaints [17]. Despite the lack of supporting evidence for the effectiveness of black cohosh, chaste tree or isoflavones in the management of menopause symptoms, the recently published North American Menopause Society "recommendations for the clinical care of midlife women" acknowledges that women often seek out this type of treatment [23].

It is worth noting that several studies on the efficacy of NHP supplementation mention a strong placebo response [13,24-28] ranging from $25 \%$ [24] to $63 \%$ [28]. Thus, it would seem that although the current literature does not show consistent efficacy evidence of the use of natural health products for menopause [12], women might still find relief of their symptoms from the placebo effect.

Our sample of OTC NHPs for menopause is a "snapshot" of products available in pharmacy chains across Canada. An apparent limitation to this study is that only nine Canadian pharmaceutical chains were investigated: between these chains, they are present in all provinces and territories in Canada and thus our sample represents a selection of the pharmacies where Canadian women would likely purchase an OTC supplement for menopausal symptoms. There are several other limitations of our study method. The stores we visited were in one city and we visited only one store per pharmacy chain. We cannot therefore comment on geographic or betweenstore variation. As well, availability does not necessarily reflect sales, although products that did not sell would be unlikely to remain for long on the store shelves. Our sample of NHPs represents the type and distribution of the 448 NHPs currently licensed by Health Canada for menopause, in terms of frequently found active ingredients and balance between single ingredient and multiple ingredient products [29]. For example, the following active ingredients are commonly in Health Canada licensed menopause NHPs: black cohosh $(51 \%)$, chaste tree $(36 \%)$, soy or red clover isoflavones (20\%); and 45\% of the licensed NHPs include a single active ingredient [29].

The objective of our study is limited to the investigation of OTC NHPs in Canada-wide pharmacies only. 
Nevertheless, apart from the store own-brand products (for example black cohosh), the products identified in this research are not restricted to the selected pharmacy chains and are likely available at independent pharmacies, naturopaths and herbalists. It is of note that many NHPs advertised for menopausal symptoms (including those identified in our study) can be bought outside of pharmacies, for example by mail order or online.

While this study is specific to the NHPs available in Canada, the use of NHPs in treating menopausal symptoms is not limited to Canada alone. Other investigations into the use of natural health therapies (black cohosh, isoflavones, phytoestrogens, and others) to treat the symptoms of menopause have been published throughout the world, including in the United Kingdom, Australia, Italy, and Turkey [30-33]. A brief informal search of pharmacy websites in Europe, Australia and USA found that Promensil ${ }^{\circ}$ products and A.Vogel ${ }^{\mathrm{m}}$ Sage, as well as many generic products of black cohosh, soy isoflavones, and chaste tree are widely available internationally. Therefore, our findings regarding the ingredients and doses of NHPs for menopause that are easily accessible to Canadian women have relevance beyond Canada.

Women are keen to make their own decisions about the use of NHPs in menopause [7], largely because of their concerns about perceived risks associated with hormone replacement therapy [4-6]. Women must balance the potential for benefit with the possible harm when making NHP decisions however the quality and type of evidence available to support women is often limited as illustrated by our study. It is important that women are aware that the regulation of these products does not imply their effectiveness, as the evidence required by Health Canada for licensing NHPs treating "low therapeutic impact conditions", including menopause, reflects "the low risk nature of these products" [10,11]. Evidencebased decision aids designed to improve the quality of decision-making are fairly common to support menopausal women's decisions about whether to use hormone replacement therapy [34]. Unfortunately few studies of decision aids regarding the use of NHPs have been undertaken $[35,36]$.

Over-the-counter NHPs are widely available for women who wish to self-manage their menopausal symptoms. Future directions for research in this area may include investigation into the high placebo response seen in controlled trials of NHP supplements for menopausal symptoms, as well as examining the efficacy and safety of combination NHP supplements; most published scientific trials have solely investigated single-ingredient supplements, though almost half of the products identified in this study available for purchase were combination products. Adequately designed decision aids would incorporate the evidence that is available to support the use of NHPs as well as discussing the information that is unknown [34].

\section{Conclusion}

Women seeking non-hormonal treatments for their menopause symptoms may prefer to use NHPs sometimes based on lay beliefs rather than evidence [37], incurring the potential of interaction with prescription medications [38,39]. Our study found that NHPs for menopausal symptoms are easily available in Canadian pharmacies. The lack of clear evidence of product efficacy, safety with respect to potential interactions with prescribed medications, and cost comparisons poses a challenge for women to make well-informed treatment choices. Further information is needed about the factors women take into account in making decisions about the purchase of NHPs.

\section{Abbreviations}

NHP: Natural health product; NPN: Health Canada Natural Product Number; OTC: Over-the-counter; SD: Standard deviation.

\section{Competing interests}

The authors declare that they have no competing interests.

\section{Authors' contributions}

JC participated in the design of the study, identified natural health products in the pharmacies, collected, entered, tabulated and analyzed the data, wrote the manuscript. SR participated in the design of the study, verified the data on natural health products, and contributed to analysis and writing. NY participated in the design of the study, provided expert pharmacist input, and contributed to analysis and writing. BCS conceived of the idea for the study, participated in the design and data collection, and contributed to analysis and writing. All authors read and approved the final manuscript.

\section{Acknowledgements}

Jennifer Croden was financially supported by a University of Alberta Women's and Children's Health Research Institute (WCHRI) summer student award. Sue Ross is the Carvazan Chair of Mature Women's Health Research. Beate Sydora and Sue Ross are supported by funding from WCHRI.

\section{Author details}

${ }^{1}$ Department of Obstetrics and Gynecology, Faculty of Medicine and Dentistry, University of Alberta, 5S131 Lois Hole Hospital for Women, Robbins Pavilion, Royal Alexandra Hospital, 10240 Kingsway Avenue NW, Edmonton, AB T5H 3 V9, Canada. ${ }^{2}$ Faculty of Pharmacy and Pharmaceutical Sciences, 3-171 Edmonton Clinic Health Academy, 11405 - 87 Avenue NW, Edmonton, AB T6G 1C9, Canada.

Received: 21 November 2014 Accepted: 12 March 2015 Published online: 27 March 2015

\section{References}

1. Utian WH. Psychosocial and socioeconomic burden of vasomotor symptoms in menopause: A comprehensive review. Health Qual Life Outcomes. 2005:3:47

2. Woods NF, Mitchell ES. Symptoms during the perimenopause: Prevalence, severity, trajectory, and significance in women's lives. Am J Med. 2005;2005(118):14-24.

3. McNagny SE. Prescribing hormone replacement therapy for menopausal symptoms. Ann Intern Med. 1999;131:605-16.

4. Barrett-Connor E, Grady D. Hormone replacement therapy, heart disease, and other considerations. Ann Rev Pub Health. 1998;19:55-72.

5. Stuenkel CA, Gass ML, Manson JE, Lobo RA, Pal L, Rebar RW, et al. A decade after the Women's Health Initiative - the experts do agree. Menopause. 2012;19:846-7. 
6. North American Menopause Society. Position statement: estrogen and progestogen use in postmenopausal women. Menopause. 2008;15:584-603.

7. Légaré F, Stacey D, Dodin S, O'Connor A, Richer M, Griffiths F, et al. Women's decision making about the use of natural health products at menopause: a needs assessment and patient decision aid. J Altern Complement Med. 2007;13:741-49.

8. Lunny CA, Fraser SN. The use of complementary and alternative medicines among a sample of Canadian menopausal-aged women. J Midwifery Womens Health. 2010;55:335-43.

9. Wathen CN. Alternatives to hormone replacement therapy: a multi-method study of women's experiences. Complement Ther Med. 2006;14:185-92.

10. Health Canada. About Natural Health Product Regulation in Canada. [http:// www.hc-sc.gc.ca/dhp-mps/prodnatur/about-apropos/index-eng.php]

11. Smith A, Jogalekar S, Gibson A. Regulation of natural health products in Canada. J Ethnopharmacol 2014, pii: S0378-8741 (14)00485-1. doi:10.1016/ j.jep.2014.06.037. [Epub ahead of print]

12. Kelley KW, Carroll DG. Evaluating the evidence for over-the-counter alternatives for relief of hot flashes in menopausal women. J Am Pharm Assoc. 2003;50:e106-15.

13. Leach MJ, Moore V. Black cohosh (Cimicifuga spp.) for menopausal symptoms. Cochrane Database of Syst Rev. 2012;9:CD007244.

14. Teschke R, Bahre R, Genthner A, Fuchs J, Schmidt-Taenzer W, Wolff A. Suspected black cohosh hepatotoxicity-challenges and pitfalls of causality assessment. Maturitas. 2009;63(4):302-14.

15. Lethaby A, Marjoribanks J, Kronenberg F, Roberts H, Eden J, Brown J. Phytoestrogens for menopausal vasomotor symptoms. Cochrane Database of Syst Rev. 2013;12, CD001395.

16. Chen MN, Lin CC, Liu C. Efficacy of phytoestrogens for menopausal symptoms: a meta-analysis and systematic review. Climacteric. 2014;29:1-21.

17. Laakmann E, Grajecki D, Doege K, zu Eulenburg C, Buhling KJ. Efficacy of Cimicifuga racemosa, Hypericum perforatum and Agnus castus in the treatment of climacteric complaints: a systematic review. Gynecol Endocrinol. 2012;28:703-9.

18. Health Canada, Site Licensing. [http://www.hc-sc.gc.ca/dhp-mps/prodnatur/ applications/licen-site-exploit/index-eng.php] (accessed 23 February 2015)

19. Health Canada, Natural Health Products Compliance and Enforcement Policy. [http://www.hc-sc.gc.ca/dhp-mps/compli-conform/info-prod/ prodnatur/complian-conform-pol-eng.php] (accessed 9 February 2015)

20. Boon HS, Kachan N. Natural health product labels: is more information always better? Patient Educ Couns. 2007:68:193-9.

21. Braun LA, Tiralongo E, Wilkinson JM, Spitzer O, Bailey M, Poole S, et al. Perceptions, use and attitudes of pharmacy customers on complementary medicines and pharmacy practice. BMC Complement Altern Med. 2010;10:38.

22. Ismail R, Taylor-Swanson L, Thomas A, Schnall JG, Cray L, Mitchell ES, et al. Effect of herbal preparations on symptom clustering during the menopausal transition. Climacteric. 2015;18:11-28.

23. Shifren JL, Gass ML, NAMS Recommendations for Clinical Care of Midlife Women Working Group. The North American Menopause Society recommendations for clinical care of midlife women. Menopause. 2014;21(10):1038-62.

24. Murkies AL, Lombard C, Strauss BJ, Wilcox G, Burger HG, Morton MS. Dietary flour supplementation decreases post-menopausal hot flushes: effect of soy and wheat. Maturitas. 1995;21:189-95.

25. Baber RJ, Templeman C, Morton T, Kelly GE, West L. Randomized placebocontrolled trial of an isoflavone supplement and menopausal symptoms in women. Climacteric. 1999;2:85-92.

26. Tice JA, Ettinger B, Ensrud K, Wallace R, Blackwell T, Cummings SR. Phytoestrogen supplements for the treatment of hot flashes: the Isoflavone Clover Extract (ICE) Study: a randomized controlled trial. JAMA. 2003;290:207-14

27. Geller SE, Shulman LP, van Breemen RB, Banuvar S, Zhou Y, Epstein G, et al Safety and efficacy of black cohosh and red clover for the management of vasomotor symptoms: a randomized controlled trial. Menopause. 2009;16:1156-66.

28. Auerbach L, Rakus J, Bauer C, Gerner C, Ullmann R, Wimmer H, et al. Pomegranate seed oil in women with menopausal symptoms: a prospective randomized, placebo-controlled, double-blinded trial. Menopause. 2012;19:426-32.
29. Health Canada, Licensed Natural Health Product Database. [http://www.hcsc.gc.ca/dhp-mps/prodnatur/applications/licen-prod/Inhpd-bdpsnheng.php] (accessed 29 October 2014)

30. Gokhale L, Sturdee DW, Parsons AD. The use of food supplements among women attending menopause clinics in the West Midlands. Journal of the British Menopause Society. 2003;9(1):32-5.

31. Gollschewski S, Anderson D, Skerman H, Lyons-Wall P. The use of complementary and alternative medications by menopausal women in South East Queensland. Womens Health Issues. 2004;14(5):165-71.

32. Cardini F, Lesi G, Lombardo F, van der Sluijs C. The use of Complementary and Alternative Medicine by women experiencing menopausal symptoms in Bologna. BMC Womens Health. 2010;10:7.

33. Koç Z, Saglam Z, Topatan S. Determination of the use of complementary and alternative medicine by women in the climacteric period in the Turkish city of Samsun. Contemp Nurse. 2013;45(2):197-209.

34. Carpenter JS, Studts JL, Byrne MM. A systematic review of menopausal symptom management decision aid trials. Maturitas. 2011;69:11-21.

35. Légaré F, Dodin S, Stacey D, Leblanc A, Tapp S. Patient decision aid on natural health products for menopausal symptoms: randomized controlled trial. Menopause Int. 2008;14:105-10.

36. Menard P, Stacey D, Légare F, Woodend K. Evaluation of a natural health product decision aid: a tool for middle aged women considering menopausal symptom relief. Maturitas. 2010;65:366-71.

37. Gratus C, Wilson S, Greenfield SM, Damery SL, Warmington SA, Grieve R, et al. The use of herbal medicines by people with cancer: a qualitative study. BMC Complement Altern Med. 2009;14:9-14.

38. Vohra S, Cvijovic K, Boon H, Foster BC, Jaeger W, LeGatt D, et al. Study of natural health product adverse reactions (SONAR): active surveillance of adverse events following concurrent natural health product and prescription drug use in community pharmacies. PLoS One. 2012;7(9):e45196.

39. Low Dog T, Marles R, Mahady G, Gardiner P, Ko R, Barnes J, et al. Assessing safety of herbal products for menopausal complaints: An international perspective. Maturitas. 2010;66:355-62.

\section{Submit your next manuscript to BioMed Central and take full advantage of:}

- Convenient online submission

- Thorough peer review

- No space constraints or color figure charges

- Immediate publication on acceptance

- Inclusion in PubMed, CAS, Scopus and Google Scholar

- Research which is freely available for redistribution 